\title{
COVID-19 lockdown: impact on psychological well-being and relationship to habit and routine modifications
}

\author{
Laura Aymerich-Franch",* \\ ${ }^{1}$ Ramón y Cajal Senior Research Fellow, Pompeu Fabra University \\ *Correspondence: \\ laura.aymerich@gmail.com
}

Keywords: COVID-19, lockdown, psychological well-being, habits and routines, social media, mental health.

\begin{abstract}
Lockdowns have been imposed around the world to contain the spread of the coronavirus pandemic. However, excessively stringent measures might be a threat to people's mental health. This study examines the impact of the COVID-19 lockdown on psychological well-being and its relationship to habit and routine modifications in a sample of 584 participants on lockdown in Spain. Habits and routines were explored in relation to media and social media use, household chores, eating, drinking and sleeping habits, working and studying, exercise and leisure, and personal care. Participants reported an important increase in negative affect as well as an important decrease in positive affect during the lockdown period, compared to before the lockdown. The decline in psychological well-being was more pronounced in younger participants. There was also a notable increase in media and social media consumption, home cleaning and tidying up, eating and sleeping, cooking and baking, reading for leisure, talking or doing activities with other people in the home, and handwashing. Increases in media and social media use, eating, and doing nothing, were significantly associated with an increase in negative affect and a decrease in positive affect. The results contribute to understanding the impact of the lockdown on psychological well-being and its relationship to habit and routine modifications during this period.
\end{abstract}

\section{$1 \quad$ Introduction}

Many governments worldwide have decreed lockdowns as a measure to contain the expansion of the COVID-19. The stringent lockdown measures implemented in some countries have raised attention from the World Health Organization (WHO), who has reminded that the measures adopted should be fully respectful of the dignity, human rights, and fundamental freedoms of persons (WHO, 2020a). The WHO highlights that "human rights require that countries should demonstrate that any such restrictive measures are necessary to curb the spread of infectious diseases in order to ultimately promote the health, rights and freedoms of individuals" as well as that "if the original rationale for imposing a restriction no longer applies, the restriction should be lifted without delay" (WHO, 2020a). While adopting social and physical distancing measures has deemed important to slow the spread of the disease (WHO, 2020b), adopting unproportionate measures might ultimately destabilize the larger public health objectives (WHO, 2020a) and lead 
to more severe outcomes, especially those associated to mental health (Brooks et al., 2002; Holmes et al., 2020; Xiang et al., 2020). Evidence of the negative impact of the COVID-19 outbreak and related lockdown measures on psychological well-being has already been reported in early severely affected countries like China (Qiu et al., 2020; Wang et al., 2020) or Italy (Rossi et al., 2020).

Lockdown situations additionally force a drastic change in habits and routines. These changes might be crucial to explain alterations on well-being and health during the lockdown and need to be examined. For instance, it has been suggested that excessive exposure to COVID-19 related information on media and social media might have a negative impact on psychological wellbeing (Garfin et al., 2020, Gao et al., 2020) or that excessive hand washing might cause hand dermatitis (Beiu et al., 2020).

The present study responds to the need for collecting data on the mental health effects of the COVID-19 pandemic, which has been highlighted as a priority (Holmes et al., 2020). In particular, it examines self-reported changes on psychological well-being as well as on habits and routines related to media and social media use, household chores, eating, drinking, and sleeping habits, working and studying, exercise and leisure, and personal care, as well as the relationship between both, during the COVID-19 lockdown situation in Spain. This country was severely affected by the pandemic and also adopted highly strict lockdown measures during this period (see SI - Lockdown measures in Spain).

The following hypothesis and research questions were examined:

$\mathrm{H}_{1}$. Based on previous studies (Rossi et al., 2020; Qiu et al., 2020; Wang et al., 2020), an important part of the sample is expected to report a decline in their psychological well-being during the lockdown period, represented by an increase in negative affect and a decrease in positive affect.

$\mathrm{RQ}_{1}$. Which habits, routines, and activities conducted at home are the most frequently reported by participants as having an increased amount of dedication during the lockdown period?

$\mathrm{RQ}_{2}$. Is there a relationship between modifications in habits, routines, and activities and psychological well-being during the lockdown? In particular, increases in which habits, routines, and activities are significantly associated with an increase in negative affect or a decrease in positive affect?

\section{$2 \quad$ Method}

\subsection{Data collection}

An online survey was distributed through social networks and mailing lists using the virtual snowball nonprobability sampling technique, utilized in similar studies (Wang et al., 2020). The survey was also posted on the website of the faculty where the study was conducted. The study got ethical approval from [hidden for peer review] University. Participants gave their consent online, at the start of the survey. The survey was anonymous. Participants did not receive 
economical compensation for participating and were free to abandon it at any time. The survey was available for 10 days (April $15^{\text {th }}-25^{\text {th }}, 2020$ ), corresponding to days 32 to 42 of the lockdown in Spain.

\subsection{Participants}

The survey was open to adult (18-65 years old) participants provided that they were not working outside the home during the lockdown (exclusion criterion). A total of 657 valid responses were obtained. However, only responses from participants physically present in Spain during the lockdown $(n=584)$ were considered for the analyses. Eighty percent of the responses were obtained in the first three days. All subsequent data and analyses include only the sample of participants in Spain.

Of the sample, $75.3 \%$ were females. The mean age was 35.3 . Regarding studies, $53.4 \%$ had completed university studies, $34.2 \%$ were currently studying at the university, and the rest had studies below university level. Regarding working condition during the lockdown, 54.3\% of the sample was working remotely from home and the rest was not working. Regarding working condition before the lockdown, $62.5 \%$ of the sample was working outside the home, $6.2 \%$ was working from home, and $31.3 \%$ was not working. Regarding people sharing the same home of the participant during the lockdown, $65.4 \%$ were only with other adults at the same home, $27.2 \%$ had minors at home, and $7.4 \%$ were by themselves. The survey was available in Spanish and English, most participants (96\%) used the Spanish version.

\subsection{Survey questions}

A particularly challenging aspect to be able to effectively attribute changes on psychological well-being and routines to the COVID-19 lockdown is the lack of data previous to this situation. This survey was specifically designed to overcome this difficulty. In particular, the survey relied on the participants' ability to compare their emotional states and habits during the lockdown to the ones previous to the start of this period. In addition to the sociodemographic and control variables reported above, the survey contained the following questions:

a) Psychological well-being. The 20-item Positive and Negative Affect Schedule (PANAS; Watson, Clark, \& Tellegen, 1988) to assess positive and negative affect during the lockdown was adapted for the study. Three additional items were added for being relevant to the lockdown situation: trapped, disoriented, and free. Participants were asked to rate how they felt during the days of lockdown compared to how they usually felt, using the response categories: more, same, less. Participants were additionally asked to list the three adjectives that described best how they were feeling during the lockdown.

b) Habits, routines, and other activities during the lockdown. Participants rated whether they performed a total of 44 habits, routines, and activities (see SI - List of activities) during the lockdown more often, same, less often, or did not do it before or now compared to before the lockdown. Participants were additionally asked to list the three activities in which they spent most of their time during the lockdown and the three activities to which they had increased the time of dedication the most, proportionally, compared to before 
the lockdown, excluding activities related to work (e.g. online meetings). They were also asked to mention any other activity not listed among the items to which they had substantially increased dedication during the lockdown.

\section{Results}

\subsection{Psychological well-being ${ }^{1}$}

An important part of the sample reported an increase in negative affect. Specifically, $57.4 \%$ felt more distressed, 51.6\% more nervous, $49.3 \%$ more irritable, $44.9 \%$ more upset, $43.6 \%$ more scared, $40.4 \%$ more jittery, $38.6 \%$ more afraid, and $28.5 \%$ more hostile. All negative affects except ashamed and guilty followed a similar pattern (i.e. most answers were concentrated in the categories more and same). These affects had a larger proportion of answers in the category less compared than in the category more, yet people feeling less ashamed or less guilty represented only $25 \%$ or less of the total answers. Also, $58.7 \%$ of the sample reported feeling more trapped, and $36.5 \%$ more disoriented. Furthermore, an important part of the sample reported a decrease in positive affect. In particular, $69.1 \%$ felt less enthusiastic, 56.5\% less active, $56.4 \%$ less excited, $42.1 \%$ less strong, $40 \%$ less determined, 39.2\% less attentive, $37 \%$ less inspired, $36.1 \%$ less alert, $34.3 \%$ less proud, and $33.8 \%$ less interested. Also, $70.2 \%$ of the sample reported feeling less free. Results split by gender are reported as supplementary information in Table S1 (SI).

Additionally, the relationship between age and positive and negative affect was also explored. For that, responses were classified as $1=$ less, $2=$ same, $3=$ more. A Spearman's rank-order correlation revealed a negative significant $(p<.05)$ correlation between age and all the PANAS negative affects, except for scared, afraid, and jittery, as well as between age and the additional items of trapped and disoriented. There was also a positive, significant $(\mathrm{p}<.05)$ correlation between age and all the PANAS positive affects, except for inspired, as well as between age and the additional item free. Results for all items are further reported in Table S2 (SI). The sample was then classified by age group and conducted the same descriptive analyses than for the general sample. The analyses revealed that negative affect consistently increased as the age group decreased and positive affect consistently decreased as the age group decreased so that in the youngest age group $(\leq 25)$, which represented $37.3 \%$ of the sample, feeling less free was reported by as high as $83 \%$ of participants, less enthusiastic by as high as $80.1 \%$, more trapped by $74.1 \%$, more distressed by $67.3 \%$, more nervous, more irritable, less active, and less excited by more than $60 \%$, more disoriented, more upset, less attentive, and less determined by more than $50 \%$, more jittery, less alert, less inspired, less proud, less interested, and less strong by more than $40 \%$, and more hostile by $39.7 \%$.

\section{Open-ended questions}

The most listed adjectives that participants used to describe how they were feeling during the lockdown were cansado/a (tired, $\mathrm{f}=70$ ), aburrido/a (bored, $\mathrm{f}=55$ ), preocupado/a (worried, $\mathrm{f}=54$ ), angustiado/a (anguished, $\mathrm{f}=48$ ), tranquilo/a (calm, $\mathrm{f}=43$ ), triste ( $\mathrm{sad}, \mathrm{f}=38$ ), nervioso/a (nervous, $\mathrm{f}=35$ ), agobiado/a (overwhelmed, $\mathrm{f}=33$ ), desorientado/a (disoriented, $\mathrm{f}=33$ ), irritable (irritable, $\mathrm{f}=32$ ), apático/a (apathetic, $\mathrm{f}=29$ ), and desmotivado/a (unmotivated, $\mathrm{f}=24$ ).

\footnotetext{
${ }^{1}$ Percentages based on three categories of response: more, same, less
} 


\subsection{Habits and routines ${ }^{2}$}

\section{Media and social media consumption}

There was a large increase in media and social media consumption, except for watching conventional TV (except News) and listening to the radio (except News). Nearly the whole sample (91.6\%) reported calling or video calling family and friends more often, $73.6 \%$ reported texting with family and friends through any platform (phone, Whatsapp, line...) more often, $62.5 \%$ reported watching Netflix or similar platforms more often, $60.1 \%$ reported participating in social media text-based groups (WhatsApp or any other social network) more often, 59\% reported doing any activity on social media other than texting, such as posting, reading, viewing images or videos, following live activities (except following News) more often, $55.6 \%$ reported following the news through any media more often, and 52.7\% reported surfing the internet (except News or social media) more often.

\section{Working and Studying}

Responses were similarly distributed across categories, working less often (34\%) and studying the same $(31.7 \%)$ were the categories with most responses, respectively.

Eating, drinking, and sleeping habits

Of the participants, $42.8 \%$ reported sleeping more often, $40.1 \%$ eating more often, $60.7 \%$ reported eating healthy as same, $64.5 \%$ did not smoke now or before, and 33.4\% reported drinking alcohol less often.

\section{Personal care}

The most remarkable increase in personal care was handwashing, with $82.5 \%$ of the participants reporting washing their hands more often. The major decrease in personal care was for shaving, with $46.4 \%$ reporting shaving less often.

\section{Household chores}

There was a general increase of dedication to household chores, which was best represented by $55.8 \%$ of the participants cleaning their homes more often, $55.7 \%$ tidying up their homes more often, $43 . \%$ rearranging objects and furniture inside the home more often, and $33.5 \%$ DIY and repair pending things inside the home more often. Cooking and baking also showed an important increase, as $54.3 \%$ of the sample cooked more often and $51.6 \%$ baked more often.

Exercise, leisure, and other activities

The activities most reported as being carried out more often during the lockdown were reading for leisure (54.5\%) and talking or doing activities with other people in your home (51.5\%). Other

\footnotetext{
${ }^{2}$ Percentages based on four categories of response: more often, same, less often, did not do it before or now
} 
activities in which the category more often was the one that obtained most responses were doing nothing (40.1\%), physical exercise, except yoga or similar $(39.9 \%)$, and board games (37\%). However, there was also an important part of the sample that reported doing less physical exercise $(30.1 \%)$. This distribution was better explained by gender: males tended to exercise less often $(43.2 \%)$ and females tended to exercise more often $(44.6 \%)$. The activity that was most reported as being carried out less often was online shopping $(35.8 \%)$.

\section{Open-ended questions}

The most listed activities in response to what activities participants spent most of their time during the lockdown were working ( $\mathrm{f}=251)$, studying $(\mathrm{f}=175)$, cooking $(\mathrm{f}=138)$, watching movies / streaming TV $(\mathrm{f}=128)$, social media / video calling $(\mathrm{f}=120)$, reading $(\mathrm{f}=118)$, physical exercise $(\mathrm{f}=106)$, and house cleaning and tidying $(\mathrm{f}=99)$. The most listed activities in response to what activities they had increased the time of dedication the most, proportionally, compared to before the lockdown, excluding activities related to work were virtual communication (video calling, texting, social networks, and related; $\mathrm{f}=230)$, cooking and baking $(\mathrm{f}=137)$, streaming $\mathrm{TV}(\mathrm{f}=131)$, house cleaning and organizing $(\mathrm{f}=125)$, reading $(\mathrm{f}=117)$, and physical exercise $(\mathrm{f}=116)$. Participants were additionally asked if there was any other activity not listed in the survey that they were substantially practicing more often during the lockdown. Being in the terrace or balcony to get fresh air or sunbathe was the most reported activity $(\mathrm{f}=37)$, followed by spending time with kids playing with them or teaching them $(\mathrm{f}=23)$, and by playing with pets $(\mathrm{f}=17)$.

\subsection{Relationship between psychological well-being and routines}

To explore the relationship between affect and habits and routines, responses were classified as $1=$ less, $2=$ same, $3=$ more / more often, and responses in the category I did not do it before or after were excluded. A positive affect scale was created adding the 10 positive affects and a negative affect scale was created adding the 10 negative affects from the PANAS scale. Passive media consumption (TV, Netflix, surfing the Internet, social media other than texting, and watching News) was positively correlated (all items $\mathrm{p}<.05$ ) with negative affect (except TV and watching News) and negatively correlated (all $p<.05)$ with positive affect. Videogaming including smartphone games was negatively correlated with positive affect $(p<.001)$. Virtual communications with family and friends, both video calls $(\mathrm{p}<.01)$ and texting $(\mathrm{p}<.05)$, were positively correlated with negative affect. Working $(\mathrm{p}<.01)$ and studying $(\mathrm{p}<.001)$ were positively correlated with positive affect. Eating was positively correlated with negative affect and negatively correlated with positive affect (both $\mathrm{p}<.001$ ) but eating healthy was correlated with positive and negative affect in the opposite direction (both $\mathrm{p}<.01$ ). Exercise-related activities, including physical exercise $(\mathrm{p}<.001)$, yoga or similar $(\mathrm{p}<.01)$, dancing $(\mathrm{p}<.001)$, and also meditation $(\mathrm{p}<.001)$ were positively correlated with positive affect and doing nothing was negatively correlated with positive affect and positively correlated with negative affect (both $\mathrm{p}<.001$ ). Handwashing, personal care, house cleaning, rearranging furniture, arts (crafts, painting, or similar), and cooking were also positively correlated with positive affect (all $\mathrm{p}<.05)$. Finally, shaving and online shopping were negatively correlated with negative affect $($ all $\mathrm{p}<.05)$. The results of the correlations are fully reported in Table S3 (SI). 
Habits and routines that positively correlated with negative affect and habits and routines that negatively correlated with positive affect were further explored using binomial logistic regression to determine whether increases in these habits were significantly associated with increases or decreases in negative affect or positive affect, respectively. For negative affect, responses of less and same were classified as no increase in negative affect $(=0)$ and responses of more were classified as increase in negative affect $(=1)$, for each item. Following this, the 10 items of negative affect were summed. Since the items were summed, participants that left one or more items in blank $(n=28)$ were excluded from this new measure. For the final scale, counts of 4 or more were considered as increase in negative affect $(=1)$ and counts of 3 or less as no increase in negative affect $(=0)$. This resulted in a new variable with a binary distribution of the results for increase in negative affect (yes/no). The distribution of responses in this new variable retained 277 cases as no increase and 279 as increase. For positive affect, responses of less were classified as decrease in positive affect $(=1)$ and responses of same or more were classified as no decrease $(=0)$, for each affect. The 10 items of the positive affect were summed. Participants that left one or more items in blank $(n=19)$ were excluded from this new measure. For the final scale, counts of 5 or more were considered as decrease in positive affect $(=1)$ and counts of 4 or less were considered as no decrease $(=0)$. This resulted in a new variable with a binary distribution of the results for decrease in positive affect (yes/no). The distribution of responses in this new variable retained 303 cases as no decrease and 262 as decrease. The cutoff point for determining increase/decrease in affect was decided based on the accuracy of the model for correctly classifying cases. For habits, responses of less, same, and did not do it before or after were classified as no increase $(=0)$ in that particular habit and responses of more as increase $(=1)$. Blank responses were not considered. This resulted in a new variable for each habit with a binary distribution that indicated increase in the habit $(=1)$ or not $(=0)$.

Only those habits that were positively and significantly correlated with negative affect or negatively and significantly correlated with positive affect (see Table S2) were examined. Physical exercise was exceptionally examined for being positively correlated with positive affect, in light of its suggested importance for promoting psychological well-being (Biddle, Fox, $\&$ Boutcher, 2003). Separate analyses were run to explore each relationship. Habits were treated as the independent variable and affect as the dependent variable in all analyses, except for eating, which was treated as the dependent variable. Increases in surfing the internet, Netflix or similar, social media (other than texting), calls/video calls with family and friends, texting family and friends, eating, and doing nothing were all significantly associated with increases in negative affect. Increases in surfing the internet, Netflix or similar, social media (other than texting), conventional TV, news through any media, videogames and games on the phone/tablet, eating and doing nothing were all significantly associated with a decrease in positive affect. Increase in physical exercise was negatively associated with a decrease in positive affect. Results are reported in Table 1 and Table 2.

\section{Discussion}

Overall, participants presented an important decline in their psychological well-being resulting from the COVID-19 lockdown, represented by an increase in negative affect, and a decrease in positive affect, which confirms the hypothesis initially proposed. These results are in line with previous works that identified a negative impact on mental health associated with the COVID-19 
outbreak and related lockdown (Rossi et al., 2020; Qiu et al., 2020; Wang et al., 2020). Additionally, the study identified that the decline in well-being was more pronounced in the younger cohorts.

Regarding habits and routines $\left(\mathrm{RQ}_{1}\right)$, a large increase in streaming $\mathrm{TV}$ and social media consumption was identified. This increase could be potentially attributed to the needs for overcoming isolation, finding alternative ways of being connected with friends and relatives, and also to the fact of having less ongoing social activities and, therefore, more free time, which is dedicated to media and social media consumption instead. There was also an increase in handwashing and house cleaning, which might suggest that participants are following the institutional recommendations in this regard.

Crucially, and in response to $\mathrm{RQ}_{2}$, the study found a significant association between decreases in psychological well-being and increases in social media and streaming TV usage, doing nothing, and eating, as well as a negative association between increase in physical exercise and decrease in positive affect. The direction of these changes (i.e. whether an increase in these habits led to a decrease in well-being or vice versa) cannot be determined from the results. While habits were generally treated as the independent variable in the analyses (except for eating) no speculation should be made in this regard. These results are in line with previous research that has associated social media consumption with a negative impact on psychological well-being (Brooks, 2015), as well as with literature that highlights the importance of physical activity and non-sedentary behavior for mental health (e.g. Biddle et al., 2003).

In light of the results, the following research directions are suggested. First, it is crucial to determine whether different levels of restrictiveness in lockdown measures affect psychological well-being differently. Activities such as being outdoors for jogging, walking, or simply to get fresh air, which were restricted in Spain as well as in other countries, are crucial for maintaining a positive functioning and preventing psychopathology and physical illnesses. Restrictions to these activities might not necessarily meet the criterion of being decisive to curb the spread of the virus (WHO, 2020a) and might cause an even larger negative impact on mental health.

Second, guilt and shame were the only negative affects with more responses in the less than in the more category. Generally, people feel guilty when they cause harm to others and then experience the need to repair damage to alleviate this emotion (Baumeister, et al., 1994). It might be interesting to explore whether people might be experiencing the lockdown as a form of punishment or damage-repair action that helps somehow relieve this moral emotion, which would be worth exploring.

Third, the younger cohorts presented a larger negative effect on psychological well-being resulting from the lockdown. Further studies are encouraged to examine whether and why generations $\mathrm{Y}$ and $\mathrm{Z}$ might be more vulnerable to the situation so that appropriate measures can be adopted to palliate this impact.

Finally, the study presents some limitations. A nonprobability sampling technique was used, and the sample size was relatively small. Therefore, the results are not meant to be inferred to the general population. Also, data related to the medical condition of the participant or their relatives 
regarding the COVID-19, socioeconomic status, geographic origin of the responses within the country, or the characteristics of the participants home (e.g. if they had an outdoors space) were not collected. Even if it was not the aim of the study to explore differences across sociodemographic variables, these variables might have been useful for providing a more indepth picture of the situation. As a last remark, participants were specifically asked to report how they felt during the lockdown compared to before. Yet, it might be difficult to disentangle completely the impact on well-being attributed to the lockdown from other concurrent factors, such as the outbreak of the pandemic itself.

To conclude, the results of the study contribute to understanding better the impact of the COVID-19 lockdown on psychological well-being by reinforcing the findings of previous studies and additionally exploring these changes in relation to habit and routine modifications.

\section{$5 \quad$ References}

Baumeister, R. F., Stillwell, A. M., \& Heatherton, T. F. (1994). Guilt: an interpersonal approach. Psychological bulletin, 115(2), 243.

Beiu, C., Mihai, M., Popa, L., et al. (2020). Frequent Hand Washing for COVID-19 Prevention Can Cause Hand Dermatitis: Management Tips. Cureus Journal of Medical Science, 12(4).

Biddle, S. J. H., Fox, K. R., \& Boutcher, S. H. (Eds). (2003). Physical activity and psychological well-being. Routledge.

Brooks, S. (2015). Does personal social media usage affect efficiency and well-being? Computers in Human Behaviour, 46, 26-37.

Brooks, S. K., Webster, R. K., Smith, L. E., Woodland, L., Wessely, S., Greenberg, N., \& Rubin, G. J. (2020). The psychological impact of quarantine and how to reduce it: rapid review of the evidence. The Lancet.

Gao, J., Zheng, P., Jia, Y., et al. (2020). Mental health problems and social media exposure during COVID-19 outbreak. Plos one, 15(4), e0231924.

Garfin, D. R., Silver, R. C., \& Holman, E. A. (2020). The novel coronavirus (COVID-2019) outbreak: Amplification of public health consequences by media exposure. Health Psychology, $39(5), 355-357$.

Holmes, E. A., O'Connor, R. C., Perry, V. H., et al. (2020). Multidisciplinary research priorities for the COVID-19 pandemic: a call for action for mental health science. The Lancet Psychiatry.

Qiu, J., Shen, B., Zhao, M., Wang, Z., Xie, B., \& Xu, Y. (2020). A nationwide survey of psychological distress among Chinese people in the COVID-19 epidemic: implications and policy recommendations. General psychiatry, 33(2). 
Rossi, R., Socci, V., Talevi, D., et al. (2020). COVID-19 pandemic and lockdown measures impact on mental health among the general population in Italy. An N=18147 web-based survey. medRxiv.

Wang, C., Pan, R., Wan, X., Tan, Y., Xu, L., Ho, C. S., \& Ho, R. C. (2020). Immediate psychological responses and associated factors during the initial stage of the 2019 coronavirus disease (COVID-19) epidemic among the general population in China. International journal of environmental research and public health, 17(5), 1729.

Watson, D., Clark, L. A., \& Tellegen, A. (1988). Development and validation of brief measures of positive and negative affect: the PANAS scales. Journal of personality and social psychology, 54(6), 1063.

WHO - World Health Organization (2020a). Addressing Human Rights as Key to the COVID19 Response. Ref. WHO/2019-nCoV/SRH/Rights/2020.1

WHO - World Health Organization (2020b). Coronavirus disease 2019 (COVID-19): situation report, 72

Xiang, Y. T., Yang, Y., Li, W., Zhang, L., Zhang, Q., Cheung, T., \& Ng, C. H. (2020). Timely mental health care for the 2019 novel coronavirus outbreak is urgently needed. The Lancet Psychiatry, 7(3), 228-229.

\section{Conflict of Interest}

The author declares that the research was conducted in the absence of any commercial or financial relationships that could be construed as a potential conflict of interest.

\section{$7 \quad$ Author Contributions}

LAF designed the study, collected and analyzed data, and wrote the manuscript.

\section{$8 \quad$ Funding}

The author is supported by Programa de Ayudas Ramón y Cajal, Ref. RYC2016-19770, funded by Agencia Estatal de Investigación (AEI), Ministerio de Ciencia, Innovación y Universidades, and the European Social Fund (ESF). 
Table 1

Increases in habits and routines positively associated with increase in negative affect

\begin{tabular}{|c|c|c|c|c|c|}
\hline & $\mathrm{b}(\mathrm{SE})$ & Wald & $p$ & OR & $95 \%$ CI OR \\
\hline \multicolumn{6}{|l|}{ MEDIA \& SOCIAL MEDIA } \\
\hline $\begin{array}{l}\text { Surfing the internet** } \\
(\mathrm{n}=552)\end{array}$ & $.48(.17)$ & 7.85 & .005 & 1.6 & {$[1.15,2.65]$} \\
\hline $\begin{array}{l}\text { Netflix or similar* } \\
(\mathrm{n}=552)\end{array}$ & $.36(.18)$ & 4.23 & .04 & 1.44 & {$[1.01,2.03]$} \\
\hline $\begin{array}{l}\text { Social Media (other than } \\
\text { texting)*** } \\
(\mathrm{n}=554)\end{array}$ & $.61(.17)$ & 12.29 & $<.001$ & 1.84 & {$[1.31,2.6]$} \\
\hline $\begin{array}{l}\text { Calls/Videocalls family and } \\
\text { friends*** } \\
(\mathrm{n}=555)\end{array}$ & $1.15(.36)$ & 10.24 & .001 & 3.17 & {$[1.56,6.42]$} \\
\hline $\begin{array}{l}\text { Texting with family and } \\
\text { friends } * * \\
(\mathrm{n}=555)\end{array}$ & $.51(.20)$ & 6.66 & .010 & 1.66 & {$[1.13,2,44]$} \\
\hline \multicolumn{6}{|l|}{$\begin{array}{l}\text { EATING, DRINKING, } \\
\text { SLEEPING }\end{array}$} \\
\hline $\begin{array}{l}\text { Eating***, } \\
(\mathrm{n}=554)\end{array}$ & $.62(.18)$ & 12.64 & $<.001$ & 1.86 & {$[1.32,2.64]$} \\
\hline \multicolumn{6}{|l|}{ LEISURE } \\
\hline $\begin{array}{l}\text { Doing nothing*** } \\
(\mathrm{n}=554)\end{array}$ & $.88(.18)$ & 24.75 & $<.001$ & 2.42 & {$[1.71,3.43]$} \\
\hline
\end{tabular}

Notes. Each row results from a separate analysis. Overall accuracy of classification $53.9 \%$ $59.9 \%$.

Model significance: $\mathrm{p}<.05^{*}, \mathrm{p}<.01^{* *}, \mathrm{p}<.001 * * *$

$\wedge$ Treated as the dependent variable 
Table 2

Increases in habits and routines positively/negatively associated with decrease in positive affect

\begin{tabular}{|c|c|c|c|c|c|}
\hline & $\mathrm{b}(\mathrm{SE})$ & Wald & $p$ & OR & $95 \%$ CI OR \\
\hline \multicolumn{6}{|l|}{ MEDIA \& SOCIAL MEDIA } \\
\hline $\begin{array}{l}\text { Surfing the internet } \\
(\mathrm{n}=561) * * *\end{array}$ & $.67(.17)$ & 15.44 & $<.001$ & 1.96 & {$[1.4,2.75]$} \\
\hline $\begin{array}{l}\text { Netflix or similar } \\
(\mathrm{n}=559)^{* * *}\end{array}$ & $.78(.18)$ & 18.76 & $<.001$ & 2.18 & {$[1.53,3.1]$} \\
\hline $\begin{array}{l}\text { Social Media (other than } \\
\text { texting)*** } \\
(\mathrm{n}=562)\end{array}$ & $.76(.17)$ & 18.62 & $<.001$ & 2.14 & {$[1.15,3.02]$} \\
\hline $\begin{array}{l}\text { Conventional TV** } \\
(\mathrm{n}=564)\end{array}$ & $.56(.19)$ & 8.20 & .004 & 1.75 & {$[1.19,2.55]$} \\
\hline $\begin{array}{l}\text { News through any media** } \\
(\mathrm{n}=560)\end{array}$ & $.45(.17)$ & 6.90 & .009 & 1.57 & {$[1,12,2,19]$} \\
\hline \multicolumn{6}{|l|}{$\begin{array}{l}\text { EATING, DRINKING, } \\
\text { SLEEPING }\end{array}$} \\
\hline $\begin{array}{l}\text { Eating } * * *, \wedge \\
(\mathrm{n}=563)\end{array}$ & $1.02(.17)$ & 33.15 & $<.001$ & 2.78 & {$[1,96,3,94]$} \\
\hline \multicolumn{6}{|l|}{ LEISURE } \\
\hline $\begin{array}{l}\text { Doing nothing*** } \\
(\mathrm{n}=563)\end{array}$ & $1.56(.18)$ & 70.93 & $<.001$ & 4.75 & {$[3.30,6.83]$} \\
\hline $\begin{array}{l}\text { Videogames, games } \\
\text { phone/tablet*** } \\
(\mathrm{n}=563)\end{array}$ & $.69(.18)$ & 14.12 & $<.001$ & 1.99 & {$[1.39,2.85]$} \\
\hline $\begin{array}{l}\text { Board games } \\
(n=562)\end{array}$ & $.32(.17)$ & 3.41 & .06 & 1.38 & {$[.98,1.95]$} \\
\hline $\begin{array}{l}\text { Exercise* } \\
(\mathrm{n}=564)\end{array}$ & $-.39(17)$ & 5.1 & .02 & .67 & {$[.48, .95]$} \\
\hline
\end{tabular}

Notes. Each row results from a separate analysis. Overall accuracy of classification $53.9 \%$ $68.6 \%$.

Model significance: $\mathrm{p}<.05^{*}, \mathrm{p}<.01^{* *}, \mathrm{p}<.001^{* * *}$

$\wedge$ Treated as the dependent variable 